\section{Genetic Diversity and Relatedness Among Cultivars of Stokes Aster}

\author{
Lyn A. Gettys ${ }^{1}$ and Dennis J. Werner ${ }^{2}$ \\ Department of Horticultural Science, North Carolina State University, \\ Raleigh, NC 27695-7609
}

Additional index words. Asteraceae, Compositae, Vernonieae, molecular markers, randomly amplified polymorphic DNA (RAPD) analysis, polymerase chain reaction, gel electrophoresis, similarity index, Stokesia laevis

\begin{abstract}
Stokes aster is a herbaceous perennial native to the southeastern United States. Stokesia is a monotypic genus belonging to the tribe Vernonieae Cass. (family Asteraceae Dumont). The level of genetic diversity within the genus is unknown. The goal of this study was to determine the level of genetic diversity and relatedness among cultivars of stokes aster. The genetic relatedness among 10 cultivars of stokes aster, one accession of Vernonia crinita Raf. (syn. V. arkansana DC.), and one accession of Rudbeckia fulgida Ait. var. sullivantii (Beadle et Boynton) Cronq. 'Goldsturm' was estimated using 74 randomly amplified polymorphic DNA (RAPD) primers. Similarity indices suggest that cultivars of stokes aster are very closely related, with values for all pairwise comparisons of cultivars of stokes aster ranging from 0.92 to 0.68 . One cultivar, 'Omega Skyrocket', had markedly lower similarity indices from the other cultivars, ranging from 0.72 to 0.68 . Similarity indices between stokes aster and Vernonia and between stokes aster and Rudbeckia were 0.44 and 0.50 , respectively.
\end{abstract}

Stokes aster [Stokesia laevis (J.Hill) Greene] is an herbaceous perennial that has potential for greater use as a landscape ornamental and as an industrial crop. The large, showy flowers of this southeastern United States native make it an ideal candidate for inclusion in the home garden, and the availability of several attractive cultivars provides gardeners and landscapers with the opportunity to choose from a variety of flower colors.

Seeds of stokes aster contain large amounts of vernolic (12,13-epoxy-cis-9-octadecenoic) acid, a fatty acid that is converted to epoxy oil products that can be used in the manufacture of plastics and adhesives (Campbell, 1981; Kleiman, 1990). Cultivation of stokes aster as an oilseed crop could potentially reduce the amount of petrochemicals used in the manufacturing process, and provide an alternative, sustainable source for raw material (Gunn and White, 1974; White, 1977).

Little is known about the origin of and level of genetic diversity among cultivars of stokes

\footnotetext{
Received for publication 2 Jan. 2001. Accepted for publication $30 \mathrm{Apr}$. 2001. This research was funded in part by the North Carolina Agricultural Research Service (NCARS) and the Perennial Plant Association. This paper is a portion of a thesis submitted by L.A.G. in partial fulfillment of the requirements for the MS degree. We thank Steve Clouse for suggestions and direction, Henry Amerson for laboratory access and assistance, and Bruce Weir for statistical consultation. Mention of a trademark, proprietary product, or vendor does not constitute a guarantee or warranty of the product by North Carolina State Univ. and does not imply its approval to the exclusion of other products or vendors that might also be suitable.

${ }^{1}$ Master of Science candidate.

${ }^{2}$ Professor.
}

aster. The development of the polymerase chain reaction (PCR) and randomly amplified polymorphic DNA (RAPD) procedures has made it possible to detect polymorphisms at the genetic level with relative ease. These techniques have been used to characterize identity and genetic relationships among cultivars in a wide range of plant species, including: buffalograss [Buchloe dactyloides (Nutt.) Engelm.] (Wu and Lin, 1994); California almonds [Prunus dulcis (Mill) D.A. Webb; P. communis (L.) Archangeli (Bartolozzi et al., 1998)]; Chinese vegetable brassicas [Brassica rapa L., B. juncea (L.) Czern., and $B$. oleracea L. sp. Alboglabra (Ren et al., 1995)]; lima beans [Phaseolus lunatus L., Nienhuis et al., (1995)]; olives [Olea europaea L. (Fabbri et al., 1995)]; and cultivars of Annona (Ronning et al., 1995). In this paper, we report the results of utilizing randomly amplified polymorphic DNA(RAPD) markers to determine the genetic relationships and degree of relatedness among cultivars of stokes aster and between stokes aster and tribal and familial representatives.

\section{Materials and Methods}

Plant materials. Ten cultivars of stokes aster were used in this study, along with two accessions representing other genera in the Asteraceae, which were included as controls. Cultivars of stokes aster included white-flowering taxa ('Alba' and 'Silver Moon'), lilacflowering taxa ('Maroon' and 'Träumerei'), a yellow-flowering taxon ('Mary Gregory'), the deep-purple flowering taxon 'Purple Parasols' (Warren, 1998), and the blue-flowering taxa 'Blue Danube', 'Klaus Jelitto', 'Wyoming', and 'Omega Skyrocket'. One specimen of ironweed [Vernonia crinita Raf. (syn. $V$. arkansana DC.)] and one specimen of 'Goldsturm' rudbeckia [Rudbeckia fulgida Ait. var. sullivantii (Beadle et Boynt.) Cronq. 'Goldsturm'] [syn. R. speciosa var. sullivantii (Beadle et Boynt.) B.L. Robinson; R. sullivantii Beadle et Boynt.] were included as tribal and familial representatives, respectively.

All cultivars of stokes aster are propagated asexually and marketed as clones with the exception of 'Träumerei', 'Alba', and 'Omega Skyrocket'. In this study, a representative specimen of 'Träumerei' was obtained from a seed-derived population (Jelitto Perennial Seed Co., Germany). 'Omega Skyrocket' was represented by an asexually propagated selection maintained and marketed by Niche Gardens, Chapel Hill, N.C. All other plant materials used in this study were obtained from the breeding collection of Dr. Dennis J. Werner at North Carolina State Univ., Raleigh, N.C.

DNA extraction. Tissue samples were harvested from young, unexpanded leaves of healthy, actively growing plants on 15 Sept. 1999. Samples were sectioned into small $\left(<1 \mathrm{~cm}^{2}\right)$ segments, then collected into four aliquots per taxon, with each aliquot weighing from 88 to $95 \mathrm{mg}$. Each aliquot was placed in a $1.5-\mathrm{mL}$ microfuge tube and stored at $-80^{\circ} \mathrm{C}$ prior to DNA extraction. Total genomic DNA was extracted from leaf tissue utilizing the DNeasy Plant Mini Kit (Qiagen, Valencia, Calif.). Leaf tissue was ground by hand to a fine powder under liquid nitrogen, then processed using the protocol, reagents, and columns accompanying the DNeasy Plant Mini Kit. DNA present in the resulting eluates was quantified by gel electrophoresis using varying concentrations of $\lambda$ DNA as standards. All DNA samples were diluted with molecular grade $\mathrm{H}_{2} \mathrm{O}$ to a standard concentration of $5 \mathrm{ng} \cdot \mu \mathrm{L}^{-1}$ before amplification.

DNA amplification. Template DNA was amplified utilizing 80 decamer oligonucleotide primers (Table 1). Sources for these primers included Operon Technologies (Alameda, Calif.), Genosys Biotechnology, (The Woodlands, Texas), and Bio-Synthesis (Lewisville, Texas). Base sequence of the primers is as defined by Operon Technologies. Primers were diluted with molecular grade $\mathrm{H}_{2} \mathrm{O}$ to a standard concentration of $6 \mathrm{ng} \cdot \mu \mathrm{L}^{-1}$ before use in amplification reactions.

Total volume of each reaction was $15 \mu \mathrm{L}$ and included 10.0 mm Tris - $\mathrm{HCl}$ ( $\mathrm{pH} 8.8), 50.0$ $\mathrm{mm} \mathrm{KCl}, 0.1 \%$ Triton-X100, $1.5 \mathrm{~mm} \mathrm{MgCl}_{2}$ (Promega, Madison, Wis.), $1 \mathrm{mg} \cdot \mathrm{mL}^{-1}$ nonacetylated BSA (New England BioLabs, Beverly, Mass.), 0.2 mm each of dATP, dCTP, dGTP, and dTTP (Roche Diagnostics, Mannheim, Germany), 0.75 units of Taq DNA polymerase (Roche Diagnostics, Mannheim, Germany), $30 \mathrm{ng}$ of a single oligonucleotide primer, and $25 \mathrm{ng}$ of genomic DNA.

Reactions were set up in 96-well Falcon U-bottom assay plates with lids (Becton Dickinson Labware, Franklin Lakes, N.J.); each well was topped with $\approx 50 \mu \mathrm{L}$ of mineral oil (E.R. Squibb \& Sons, Princeton, N.J.) to prevent desiccation, and assay plates were centrifuged before amplification. Reactions were amplified immediately utilizing a MJ Research model PTC-100 thermal cycler (MJ Research, Watertown, Mass.). Cycle param- 
Table 1. RAPD primers used for amplification of genomic DNA and analysis of relationship between cultivars of stokes aster, tribal representative ironweed, and familial representative 'Goldsturm' rudbeckia, total number of bands produced, and number of polymorphic bands. Only those primers that revealed a polymorphism among cultivars of Stokes aster are shown.

\begin{tabular}{|c|c|c|c|c|c|}
\hline Primer & $\begin{array}{c}\text { Total no. } \\
\text { bands }\end{array}$ & $\begin{array}{l}\text { No. polymorphic } \\
\text { bands }^{y}\end{array}$ & Primer & $\begin{array}{l}\text { Total no. } \\
\text { bands }\end{array}$ & $\begin{array}{l}\text { No. polymorphic } \\
\text { bands }^{y}\end{array}$ \\
\hline$\overline{\mathrm{A} 06}$ & 10 & 9 & AT15 & 5 & 1 \\
\hline A07 & 4 & 2 & $\mathrm{C} 12$ & 14 & 8 \\
\hline A09 & 10 & 2 & D03 & 9 & 4 \\
\hline A 10 & 7 & 1 & D10 & 8 & 2 \\
\hline A11 & 5 & 4 & D11 & 8 & 5 \\
\hline A12 & 5 & 5 & D16 & 6 & 3 \\
\hline A 15 & 4 & 2 & D20 & 7 & 3 \\
\hline A 16 & 3 & 3 & F03 & 9 & 4 \\
\hline A 17 & 7 & 5 & F13 & 7 & 4 \\
\hline A19 & 7 & 4 & G02 & 9 & 4 \\
\hline A 20 & 8 & 4 & G04 & 6 & 3 \\
\hline B01 & 11 & 6 & G06 & 13 & 6 \\
\hline B02 & 3 & 3 & G07 & 7 & 5 \\
\hline B03 & 4 & 1 & G08 & 9 & 3 \\
\hline B04 & 5 & 2 & G09 & 3 & 2 \\
\hline B05 & 4 & 3 & G10 & 12 & 4 \\
\hline B06 & 7 & 2 & G11 & 11 & 4 \\
\hline B07 & 5 & 1 & G12 & 5 & 2 \\
\hline B08 & 8 & 5 & G13 & 7 & 2 \\
\hline B09 & 10 & 5 & G14 & 6 & 3 \\
\hline B10 & 7 & 3 & G15 & 1 & 1 \\
\hline B11 & 9 & 5 & G17 & 6 & 2 \\
\hline B 12 & 9 & 3 & G18 & 6 & 4 \\
\hline B13 & 13 & 9 & $\mathrm{H} 20$ & 6 & 3 \\
\hline B 15 & 7 & 3 & I10 & 5 & 5 \\
\hline B16 & 13 & 10 & J04 & 2 & 1 \\
\hline B17 & 9 & 4 & J07 & 4 & 1 \\
\hline B 18 & 10 & 5 & K01 & 6 & 5 \\
\hline B19 & 3 & 3 & K14 & 11 & 6 \\
\hline B20 & 7 & 3 & K19 & 8 & 3 \\
\hline AK06 & 12 & 6 & N09 & 6 & 4 \\
\hline AK19 & 13 & 8 & Q05 & 8 & 3 \\
\hline AP06 & 10 & 3 & R16 & 10 & 9 \\
\hline AP11 & 5 & 3 & W13 & 9 & 3 \\
\hline AP12 & 15 & 5 & & & \\
\hline
\end{tabular}

${ }^{2}$ No. bands $=$ total number of bands produced by the primer

${ }^{y}$ No. polymorphic bands $=$ number of bands that are useful for distinguishing at least one cultivar of stokes aster from the other cultivars of stokes aster.

eters consisted of 41 cycles of $92{ }^{\circ} \mathrm{C}$ for 1 $\min , 35^{\circ} \mathrm{C}$ for $1 \mathrm{~min}$, and $72{ }^{\circ} \mathrm{C}$ for $2 \mathrm{~min}$. Two independent replicates were performed for each amplification reaction. The resulting PCR products were resolved and analyzed utilizing gel electrophoresis with $1.5 \%$ agarose gel in $1 \times$ TBE buffer. Gels were charged with $13 \mu \mathrm{L}$ of $1 \%$ ethidium bromide solution (Fisher Biotech, Fair Lawn, N.J.) and run for $\approx 5 \mathrm{~h}$ at $150 \mathrm{~V}$ in a Gator model No. A3-1 horizontal electrophoresis unit (Owl Separation Systems, Portsmouth, N.H.).

Analysis. Amplification product sizes were estimated using a 1-Kb DNA ladder (Gibco BRL, Grand Island, N.Y.). Products were visualized with ultraviolet light and digitally photographed using a Macintosh computer equipped with the Kodak Digital Science Imaging System that included a Kodak Digital Science Electrophoresis Documentation and Analysis DC120 digital camera and hood, and Kodak Digital Science 1D Image Analysis software (Eastman-Kodak Co., Scientific Imaging Systems, Rochester, N.Y.). Images were saved as black-and-white TIFF (Tagged Image File Format) images and scored in a Windows NT 4.0 environment using AFLPQuantar 1.0 software (Keygene N.V., Wageningen, The Netherlands). Reproduc- ible bands were scored as 1 (present) or 0 (absent). Each amplified fragment was coded with the primer number used to generate the fragment and the approximate size (number of base pairs) of the fragment. Genetic distance estimates (d-values) were calculated by hand as the number of shared bands between two taxa divided by the number of total bands (Sneath and Sokal, 1973).

\section{Results and Discussion}

Seventy-four of the 80 decamer oligonucleotide primers $(92.5 \%)$ utilized in this experiment yielded reproducible polymorphic bands (Fig. 1), either for polymorphisms among cultivars of stokes aster (69 informative primers) (Table 1), or between stokes aster and the tribal or familial representatives (74 informative primers). Primers that failed to yield reproducible bands over the two independent replicates were eliminated from the data set. The 74 decamer oligonucleotide primers produced a total of 531 reproducible bands; $264(49.7 \%)$ of the bands revealed polymorphisms among cultivars of stokes aster. The remaining 267 (50.3\%) bands were monomorphic among cultivars, but useful for separating stokes aster from the tribal or familial representatives. An average of 7.2 bands was produced per primer; on average, 3.6 of these bands exhibited polymorphisms among cultivars of stokes aster.

Similarity indices (Table 2) were calculated for all pairwise comparisons of taxa by determining the number of shared bands and dividing by the number of total bands. These data suggest that cultivars of stokes aster are very closely related, with similarity indices between pairs of cultivars of stokes aster ranging from 0.92 to 0.68 . The similarity indices between 'Omega Skyrocket' and each of the other nine cultivars of stokes aster were significantly lower than similarity indices between all pairwise comparisons of the other cultivars of stokes aster. Pairwise comparisons between 'Omega Skyrocket' and each of the other cultivars ranged from 0.72 to 0.68 , while similarity indices between pairwise comparisons of the other nine cultivars ranged from 0.92 to 0.86 .

Similarity indices between cultivars of stokes aster and the tribal representative ironweed ranged from 0.46 to 0.38 . Also, the similarity index resulting from the pairwise comparison of 'Omega Skyrocket' and ironweed was significantly lower than the indices comparing all other cultivars of stokes aster to ironweed. The similarity index between ironweed and 'Omega Skyrocket' was 0.38 , while similarity indices for all pairwise comparisons between ironweed and the other nine cultivars of stokes aster ranged from 0.46 to 0.43 .

Similarity indices between cultivars of stokes aster and the familial representative 'Goldsturm' rudbeckia ranged from 0.51 to 0.43 . Also, the similarity index resulting from the pairwise comparison of 'Omega Skyrocket' and 'Goldsturm' rudbeckia was significantly lower than the indices comparing all other cultivars of stokes aster to the familial representative. The similarity index between 'Goldsturm' rudbeckia and 'Omega Skyrocket' was 0.43 , while similarity indices for all pairwise comparisons between 'Goldsturm' rudbeckia and the other nine cultivars of stokes aster ranged from 0.51 to 0.48 .

The parenthetical similarity values in Table 2 were calculated to determine similarity between an individual cultivar of stokes aster and the group of all other cultivars of stokes aster; these values were derived by computing the mean of all pairwise comparisons between an individual cultivar and all other cultivars. Similarity values between individual cultivars and the group of all other cultivars ranged from 0.88 to 0.70 (Table 2). 'Omega Skyrocket' again produced similarity values that were significantly lower than those calculated for all other cultivars. The mean of pairwise comparisons between 'Omega Skyrocket' and all other cultivars was only 0.70 , while values calculated by comparing each of the other nine cultivars of stokes aster to the group of all other cultivars ranged from 0.88 to 0.85 . Similarity values for each set of individual cultivars and the group of all other cultivars increased with the removal of 'Omega Skyrocket' from the data set. When comparisons between individual cultivars and the group of 

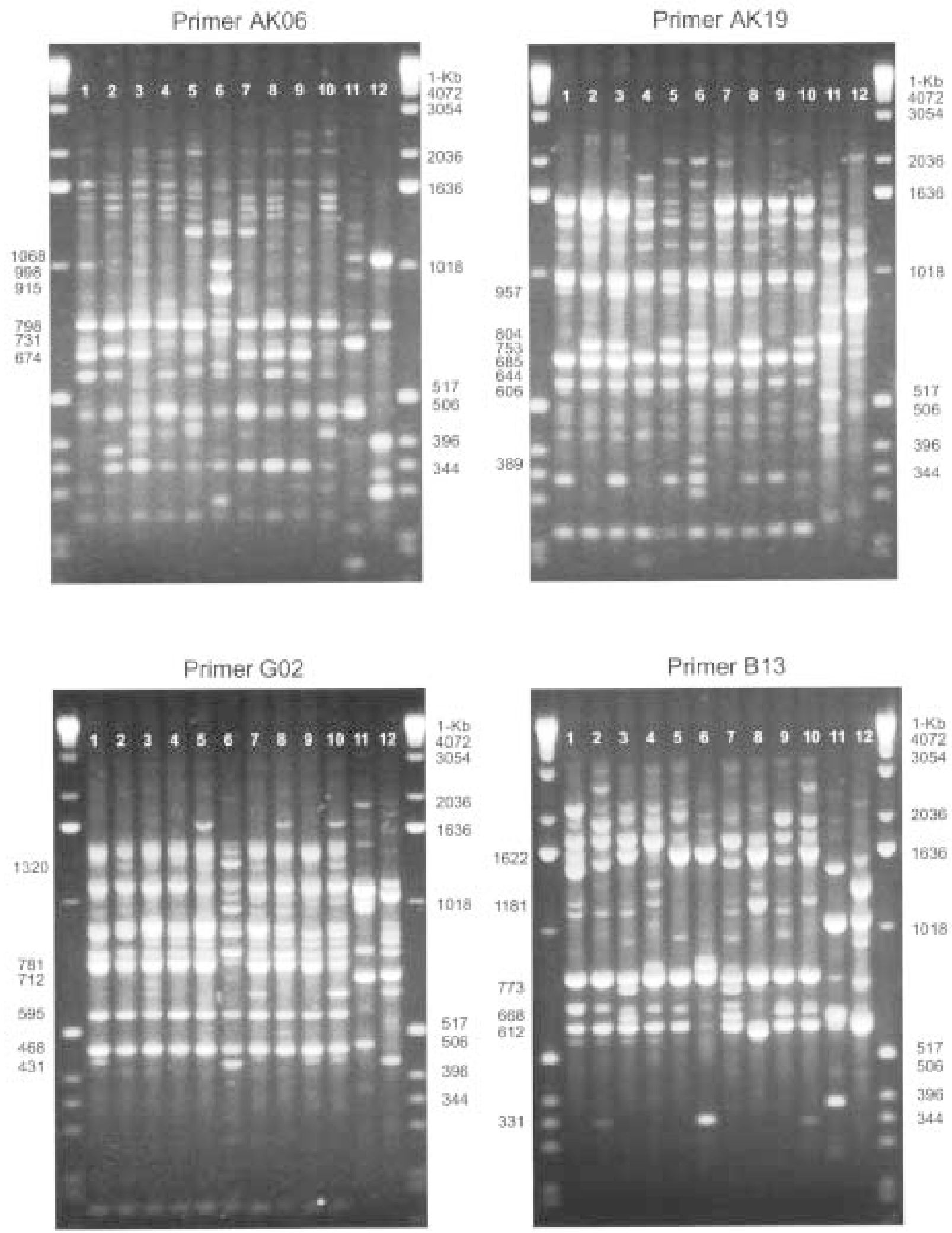

Fig. 1. RAPD banding patterns in four representative gels (Primer AK06, Primer AK19, Primer G02, and Primer B13) of cultivars of stokes aster and tribal and familial representatives. Lane 1 = 'Alba', lane 2 = 'Blue Danube', lane $3=$ 'Klaus Jelitto', lane 4 = 'Maroon', lane $5=$ 'Mary Gregory', lane $6=$ 'Omega Skyrocket', lane $7=$ 'Purple Parasols', lane 8= 'Silver Moon', lane 9= 'Träumerei', lane 10 = 'Wyoming' (cultivars of stokes aster); lane 11 = ironweed (tribal representative); lane $12=$ 'Goldsturm' rudbeckia (familial representative). Unlabeled end lanes $=1 \mathrm{~Kb}$ molecular weight ladder. Bands produced by $1 \mathrm{~Kb}$ ladder are labeled to the right of each gel with approximate molecular weight in kilobases. Reproducible polymorphic bands among cultivars of stokes aster, tribal representative, and familial representative are labeled to the left of each gel with approximate molecular weight in kilobases. 
Table 2. Pairwise coefficient of similarity indices between cultivars of stokes aster and tribal and familial representatives. Values represent the number of shared RAPD markers between a pair of taxa divided by the total number of RAPD markers.

\begin{tabular}{|c|c|c|c|c|c|c|c|c|c|c|c|c|}
\hline Taxa $^{2}$ & $\mathrm{AL}$ & BD & KJ & TM & MG & OSR & PP & SM & TR & WY & VR & $\mathrm{RB}$ \\
\hline$\overline{\mathrm{AL}(0.87)}$ & 1.00 & & & & & & & & & & & \\
\hline $\mathrm{BID}(0.86)$ & 0.88 & 1.00 & & & & & & & & & & \\
\hline $\mathrm{KJ}(0.86)$ & 0.87 & 0.88 & 1.00 & & & & & & & & & \\
\hline $\mathrm{TM}(0.87)$ & 0.89 & 0.89 & 0.86 & 1.00 & & & & & & & & \\
\hline MG (0.85) & 0.87 & 0.86 & 0.85 & 0.87 & 1.00 & & & & & & & \\
\hline OSR $(0.70)$ & 0.72 & 0.71 & 0.68 & 0.70 & 0.70 & 1.00 & & & & & & \\
\hline $\mathrm{PP}(0.87)$ & 0.90 & 0.88 & 0.89 & 0.92 & 0.87 & 0.69 & 1.00 & & & & & \\
\hline $\mathrm{SM}(0.86)$ & 0.88 & 0.88 & 0.88 & 0.88 & 0.87 & 0.69 & 0.89 & 1.00 & & & & \\
\hline TR (0.88) & 0.91 & 0.88 & 0.89 & 0.90 & 0.86 & 0.69 & 0.89 & 0.89 & 1.00 & & & \\
\hline WY $(0.88)$ & 0.90 & 0.92 & 0.90 & 0.89 & 0.88 & 0.70 & 0.89 & 0.89 & 0.91 & 1.00 & & \\
\hline VR $(0.44)$ & 0.45 & 0.46 & 0.44 & 0.46 & 0.44 & 0.38 & 0.44 & 0.43 & 0.46 & 0.43 & 1.00 & \\
\hline $\mathrm{RB}(0.50)$ & 0.51 & 0.50 & 0.51 & 0.51 & 0.49 & 0.43 & 0.50 & 0.48 & 0.51 & 0.51 & 0.55 & 1.00 \\
\hline
\end{tabular}

${ }^{2} \mathrm{AL}=$ 'Alba', BD = 'Blue Danube', KJ = 'Klaus Jelitto', TM = 'Maroon', MG = 'Mary Gregory', OSR = 'Omega Skyrocket', PP = 'Purple Parasols', SM = 'Silver Moon', TR = 'Träumerei', WY = 'Wyoming' (cultivars of stokes aster); VR = ironweed (tribal representative); RB = 'Goldsturm' rudbeckia (familial representative). Number in parentheses is the mean similarity value between that taxon and all other cultivars of stokes aster.

all other cultivars excluding 'Omega Skyrocket' were calculated, similarity values ranged from 0.90 to 0.87 (data not shown).

The similarity value between the tribal representative ironweed and the group of all cultivars of stokes aster was 0.44 . This value changed only slightly to 0.45 with the removal of 'Omega Skyrocket' from the data set. The similarity value between cultivars of stokes aster and the familial representative 'Goldsturm' rudbeckia was 0.50 and was not affected by the removal of 'Omega Skyrocket' from the data set.

The pedigree of most cultivars of stokes aster is unknown, as many were selected from cultivated gardens or existing native populations. 'Mary Gregory', the only yellow-flowered cultivar, reportedly was found in a garden population by M. Creel of the South Carolina Dept. of Natural Resources in Columbia, S.C. (M. Creel, personal communication). However, no formal documentation of the parentage of 'Mary Gregory' has been recorded. The patented cultivar 'Purple Parasols' (U.S. Patent \#010660) was selected in Kentucky and registered by C. Warren of North American Lily and Floral in 1998. 'Purple Parasols' is described as having flowers that are light blue initially, then change to dark-blue, bluish-purple, reddish-purple, and dark hot-pink as the flowers age. The parentage of 'Purple Parasols' is unknown.

'Omega Skyrocket' was derived from a population of plants found growing naturally in Colquitt County, Ga. by R. Determann and O. Johnson of the Atlanta Botanical Garden. The original population was comprised of a group of plants that were morphologically similar to one another, but possessed a growth habit different than the wild type stokes aster. 'Omega Skyrocket' has flowers borne on peduncles that are $>1 \mathrm{~m}$ in length while the other cultivars of stokes aster rarely reach heights $>70 \mathrm{~cm}$ and bear flowers in, or slightly above, the canopy of the plant. The area where 'Omega Skyrocket' was originally found has since been developed into cultivated pastureland, so the original population of plants has been destroyed. Fortunately, seeds were collected from many specimens within the population before destruction of the habitat; therefore, some level of germplasm preservation was established (M. Determann, Atlanta Botanical Garden, personal communication).

These molecular data suggest that while all cultivars of stokes aster are closely related, 'Omega Skyrocket' is somewhat divergent from the group as a whole. The substantial effect of the removal of 'Omega Skyrocket' from the data set implies that 'Omega Skyrocket' has a different genetic base than the rest of the cultivars of stokes aster. These findings reflect the distinctiveness of the morphological characters, such as greatly increased peduncle height, that separate 'Omega Skyrocket' from the other cultivars of stokes aster.

\section{Literature Cited}

Bailey, L.H. 1949. Manual of cultivated plants. Revised ed. Macmillan, New York.

Bartolozzi, F., M.L. Warburton, S. Arulsekar, and T.M. Gradziel. 1998. Genetic characterization and relatedness among California almond cultivars and breeding lines detected by randomly amplified polymorphic DNA (RAPD) analysis. J. Amer. Soc. Hort. Sci. 123:381-387.

Campbell, T.A. 1981. Agronomic potential of stokes aster. American Oil Chemists' Society Monograph 9:287-295. Amer. Oil Chem. Soc., Champaign, Ill.
Fabbri, A., J.I. Hormaza, and V.S. Polito. 1995. Random amplified polymorphic DNA analysis of olive (Olea europaea L.) cultivars. J. Amer. Soc. Hort. Sci. 120:538-542.

Greene, E.L. 1893. Observations on the Compositae-I. Erythea 1(1):1-4.

Gunn, C.R. and G.A. White. 1974. Stokesia laevis: Taxonomy and economic value. Econ. Bot. 28:130-135.

Kleiman, R. 1990. Chemistry of new industrial oilseed crops, p. 196-203. In: J. Janick and J.E. Simons (eds.). Advances in new crops: Proceedings of the first national symposium 'New crops: Research, development, economics'. Indianapolis.

Nienhuis, J., J. Tivang, P. Skroch, and J.B. dos Santos. 1995. Genetic relationships among cultivars and landraces of lima bean (Phaseolus lunatus L.) as measured by RAPD markers. J. Amer. Soc. Hort. Sci. 120:300-306.

Ren, J., J.R. McFerson, R. Li, S. Kresovich, and W.F. Lamboy. 1995. Identities and relationships among Chinese vegetable brassicas as determined by random amplified polymorphic DNA markers. J. Amer. Soc. Hort. Sci. 120:548 555.

Ronning, C.M., R.J. Schnell, and S. Gazit. 1995. Using randomly amplified polymorphic DNA (RAPD) markers to identify Annona cultivars. J. Amer. Soc. Hort. Sci. 120:726-729.

Sneath, P.H.A. and R.R. Sokal. 1973. Numerical taxonomy: the principles and practices of numerical classification. W.H. Freeman, San Francisco.

Warren, C.S. 1998. U. S. Patent\#PP010660. Stokesia plant (sic) Purple Parasols.

White, G.A. 1977. Plant introductions-A source of new crops, p. 17-24. In: D.S. Seigler (ed.). Crop resources: Proceedings of the 17th annual meeting of the Society for Economic Botany. Academic Press, New York.

Wu, L. and H. Lin. 1994. Identifying buffalograss [Buchloe dactyloides (Nutt.) Engelm.] cultivar breeding lines using random amplified polymorphic DNA (RAPD) markers. J. Amer. Soc. Hort. Sci. 119:126-130. 